\title{
Rancang Bangun Sistem Informasi Audit Mutu Internal Berbasis IAPS 4.0
}

\author{
${ }^{1}$ Suryo Widiantoro*, ${ }^{2}$ Yodi \\ ${ }^{1,2}$ Program Studi Sistem Informasi, Fakultas Komputer, Universitas Universal \\ Kompleks Maha Vihara Duta Maitreya, Batam
}

\author{
Alamat Surat \\ Email:*suryo.widiantoro@gmail.com,yodilabs@gmail.com
}

Article History:

Diajukan: 26 September 2020; Direvisi: 24 Oktober 2020; Accepted: 01 Nopember 2020

\begin{abstract}
ABSTRAK
Salah satu sistem akademik dalam dunia pendidikan khususnya Perguruan Tinggi yaitu Audit Mutu Internal (AMI). AMI yang dikoordinir oleh Lembaga Penjaminan Mutu (LPM) dalam suatu perguruan tinggi mendukung terwujudnya nilai perguruan tinggi dalam bentuk akreditasi. Tujuan dari kegiatan AMI yaitu untuk memastikan aktivitas didalam perguruan tinggi sesuai dengan standar yang ditetapkan sebagai proses untuk menerapkan budaya mutu perguruan tinggi. Aktivitas yang berlangsung tidak terlepas dari pelayanan yang diberikan kepada para konsumen seperti mahasiswa, stakeholder dan alumni baik secara akademik dan non akademik. Berdasarkan hal tersebut maka rancang bangun sistem AMI berbasis Instrumen Akreditasi Program Studi (IAPS) 4.0 sangat penting untuk mendukung dan mempermudah dalam melakukan evaluasi terhadap kebijakan pelayanan yang diberikan untuk menjamin kepuasan konsumen. Pendekatan rancang bangun yang digunakan yaitu Unified Modelling Language (UML) sebagai model rancangan yang menggambarkan secara jelas mengenai aspek sistem dengan pengembangan sesuai kebutuhan yang lebih sederhana.
\end{abstract}

Kata kunci: rancang bangun; audit mutu internal; IAPS 4.0

ABSTRACT

One of the educational systems in education, mostly higher education, is the Internal Quality Audit (IQA). IQA coordinated by the Quality Assurance Agency (QAA) in a tertiary institution supports the realization of tertiary institutions' value in accreditation. The purpose of IQA activities is to ensure that the tertiary institution's activities are by the standards set to apply tertiary quality culture. Activities that take place are inseparable from the services provided to consumers, stakeholders, and alumni, both academically and non-academically. Based on this, the IQA system's design based on the Study Program Accreditation Instrument (SPAI) 4.0 is essential to support and facilitate the evaluation of service policies to ensure customer satisfaction. The design approach used is the Unified Modeling Language (UML) as a design model that clearly illustrates aspects of the system with development according to more specific needs.

Keywords: design; internal quality audit; IAPS 4.0

\section{PENDAHULUAN}

Pada perubahan aturan perundang-undangan Badan Akreditasi Nasional Perguruan Tinggi No 2 tahun 2019 tanggal 25 maret 2019 mengenai Panduan Penyusunan Laporan Evaluasi Diri dan Panduan Penyusunan Laporan Kinerja Program Studi dalam Instrumen Akreditasi Program Studi (BAN-PT, 2019), menunjukkan adanya peran Instrumen Akreditasi Program Studi (IAPS 4.0). Hal ini semakin memperluas penerapan teknologi informasi (TI) dalam dunia perguruan tinggi. 
Pemanfaatan TI terhadap pangkalan data PD DIKTI menjadi sangat penting untuk memantau data dan aktifitas secara transparan, sehingga kedepannya proses akreditasi oleh BAN-PT sudah tidak wajib untuk melakukan kunjungan, kecuali bila ada yang ingin dikonfirmasi oleh asesor kepada pihak terkait. Hal ini menunjukkan bahwa peran teknologi yang mampu memberikan data dan informasi yang dapat dipercaya. Perguruan tinggi perlu memastikan budaya mutu yang dimiliki dapat berjalan dengan baik. Untuk memastikan hal tersebut maka Lembaga Penjaminan Mutu (LPM) harus berfungsi secara konsisten. Hal ini terutama dikaitkan dengan pelaksanaan siklus SPMI, yaitu Penetapan, Pelaksanaan, Evaluasi, Pengendalian dan Peningkatan (PPEPP).

Audit mutu internal (AMI) perguruan tinggi dilakukan melalui siklus evaluasi dan dilakukan oleh petugas yang ditugaskan secara resmi oleh pimpinan perguruan tinggi dengan tujuan untuk memberikan gambaran aktivitas perguruan tinggi yang telah dijalankan terhadap prosedur dan standar yang telah ditetapkan. Audit mutu internal merupakan proses penilaian yang dilaksanakan berdasarkan prosedur dan standar perguruan tinggi secara objektif terhadap kegiatan operasional dan keberagaman kontrol yang ada di dalam perguruan tinggi. Proses audit yang dilaksanakan harus terdokumentasi dengan baik dan benar sebagai bukti dan objektifitas penilaian. Instrumen Akreditasi Program Studi (IAPS) didukung oleh bukti dan proses yang terjadi dalam siklus PPEPP yang terdiri dari Evaluasi Diri, Laporan Kinerja Program Studi (LKPS) dan Laporan Kinerja Perguruan Tinggi (LKPT). Proses akreditasi benar-benar transparan, efektif dan efisien. Namun apabila perguruan tingggi tidak sanggup untuk mengikuti instrumen yang diberlakukan maka sanksi terberat bisa diberlakukan, misalnya perguruan tinggi digabung atau disatukan dengan perguruan tinggi lain untuk meningkatkan kinerja. Delapan puluh persen kegagalan organisasi disebabkan oleh tidak adanya dukungan manajemen administrasi yang baik. Dibeberapa penelitian menyebutkan bahwa banyaknya pencatatan secara tradisional dapat memunculkan beberapa permasalahan, diantaranya duplikasi data, kesalahan, kelalaian dan kurangnya pengendalian internal (Nugroho et.al, 2016). Oleh sebab itu untuk membantu perguruan tinggi dalam menghadapi Standar Penjaminan Mutu Eksternal (SPME) dalam tahapan Evaluasi, Penetapan dan Pemantauan (EPP) terkait IAPS maka, diperlukan suatu persiapan dengan memanfaatkan teknologi informasi. Langkah awal dari persiapan tersebut adalah dengan cara Menyusun sebuaah rancang bangun sistem informasi AMI berbasis IAPS 4.0. Analisis sistem berdasarkan kebutuhan pengguna, sehingga dapat memberikan gambaran konseptual keseluruhan sistem yang dikembangkan.

Penelitian terkait perancangan pada tahun 2020 dilakukan oleh Fittryani dan Made terhadap optimalisasi perubahan jadwal kuliah berbasis Mobile pada STIKI Indonesia. Rancang bangun sistem dilakukan untuk memberikan kemudahan dalam proses distribusi informasi kepada mahasiswa dan dosen secara cepat, tepat dan akurat (Fittryani,et.al). Penelitian mengenai rancang bangun juga di lakukan oleh Cakra, dkk pada tahun 2020. Rancang bangun mengenai sistem informasi pengolahan nilai siswa pada SMK Kesehatan Panca Atma Jaya. Adapun permasalahan pada sistem yang ada sebelumnya yaitu pengumpulan nilai yang sering terlambat. Hal ini sedikit menghambat proses penyusunan rapor. Berdasarkan rancang bangun yang dibuat dapat disimpulkan bahwa telah sesuai dengan kebutuhan sistem yang didukung dengan pengujian fungsional dan non fungsional (Cakra, et.al).

Penelitian mengenai Sistem Informasi Audit Mutu Internal Satuan Penjaminan Mutu (SPM) Unjani. Divisi SPM Unjani melaksanakan audit mutu internal, ISO maupun BAN-PT, dengan pengelolaan secara manual. Hal ini menyebabkan pengarsipan data dan proses perhitungan kurang akurat. Hasil penelitian ini berupa suatu sistem pengelolaan kegiatan audit mutu internal yang mengacu pada SN DIKTI. Dengan adanya system ini dapat mempermudah SPM dalam mengelola Audit Mutu Internal di lingkungan perguruan tinggi, mulai dari Persiapan Awal Audit, Penjadualan Audit, dan Laporan Hasil Audit (Komarudin, et.al). Penelitian yang dilakukan oleh Chandra, N.A dan Nurjannah, S. 2018 mengenai Aplikasi Audit Mutu Internal online Studi kasus SPM Politeknik Negeri Bandung. Audit Mutu Internal yang dilakukan di Politeknik Negeri Bandung menggunakan suatu aplikasi yang bernama PAMIOL. Penyimpanan data pada aplikasi PAMIOL menggunakan link data dalam format Excel dan Word. Penelitian ini melakukan perbaikan terhadap sistem aplikasi 
berdasarkan analisis sistem dan instrumen audit BORANG 3A BAN PT. Hasil penelitian berupa perbaikan sistem baru bernama AMI Online dengan kemampuan memasukkan data audit yang bersifat dinamis. Hal ini dapat mengakomodasi perubahan instrumen pertanyaan apabila diperlukan. Penggunaan RDBMS mampu menampung data jawaban auditee sehingga dapat dengan mudah bisa ditelusuri pada saat dibutuhkan. Aplikasi ini digunakan untuk membantu proses audit mutu internal perguruan tinggi (Nugraha et.al, 2018). Pada tahun 2017 dilakukan penelitian mengenai Aplikasi Audit Mutu Akademik Internal dengan Pendekatan Extreme Programming. Penelitian ini bertujuan untuk memberikan kemudahan terhadap pendokumentasian dokumen mutu akademik perguruan tinggi, mempermudah dalam pemetaan resiko mutu perguruan tinggi. Sistem yang dihasilkan mendukung perguruan tinggi dalam meningkatkan akreditasi program studi, mempermudah asesor BAN-PT dalam akses dokumen yang dibutuhkan untuk penilaian akreditasi (Adelin et.al, 2017).

\section{METODE}

Metode yang digunakan dalam penelitian ini menggunakan pendekatan Unified Modelling Language dimana diagram yang digunakan adalah use case diagram dan sequence diagram.

\subsection{Unified Modelling Language}

UML berfungsi sebagai jembatan komunikasi terhadap aspek-aspek yang telibat dalam sistem perangkat lunak berorientasi objek, dalam bentuk model visual (Marfuah et.al, 2017). Teknik pemrograman berorientasi objek disebut juga sebagai teknik pemrograman modern, di mana segala sesuatu dianggap sebagai objek (Utariani et.al). Adapun UML yang digunakan dalam perancangan ini ada 2 jenis diantaranya:

1. Use case Diagram: Desain visual ini memperlihatkan aktor-aktor dan himpunan use case yang terlibat dalam sistem (Wijaya et.al, 2018). Adapun beberapa komponen yang digunakan diantaranya:

a. Actor: User/pengguna sistem yang mengharapkan layanan dari sistem.

b. Use case: Berbentuk oval dan mewakili fungsi yang akan dijalankan sistem sebagai respon yang dipicu oleh actor.

c. System boundary (batas sistem) diindikasikan melalui gambar kotak disekeliling seluruh use case dengan actor berada di luar kotak.

d. Association menunjukkan actor mana yang butuh interaksi dengan use case tertentu dengan menggambar garis yang menghubungkan actor dengan use case yang diinginkan.

2. Sequence diagram: Desain visual ini memperlihatkan interaksi yang terjadi pada suatu aktor terhadap sistem yang ditekankan pada pengiriman pesan dalam suatu waktu tertentu. Penggambaran sequence diagram akan semakin banyak sesuai dengan use case yang akan didefenisikan (Putra et.al, 2019). Adapun beberapa komponen yang digunakan diantaranya :

a. Object: Bentuk kotak yang mewakili sebuah class atau object yang memperlihatkan prilaku objek di dalam sistem.

b. Activation boxes: Bentuk persegi panjang memperlihatkan durasi waktu yang diperlukan bagi suatu objek dalam menyelesaiakan tugas.

c. Actors: Bentuk stick figure pengguna yang melakukan interaksi terhadap sistem.

d. Lifeline: Bentuk garis putus-putus berisi nama objek dan biasanya digunakan untuk memperlihatkan aktivitas objek.

\subsection{Audit Mutu Internal (AMI)}

AMI merupakan suatu proses terdokumentasi untuk melihat secara sistematik apakah aktivitas yang dilakukan telah sesuai dengan standar yang ditetapkan yang bertujuan untuk mencapai tujuan institusi (SPMI, 2019). AMI juga sebagai bagian dari kriteria akreditasi. Salah satu siklus Sistem Penjaminan Mutu Internal (SPMI) yaitu melakukan evaluasi. Evaluasi dapat dilakukan melalui AMI. Proses SPMI sebagaimana Gambar 1. 


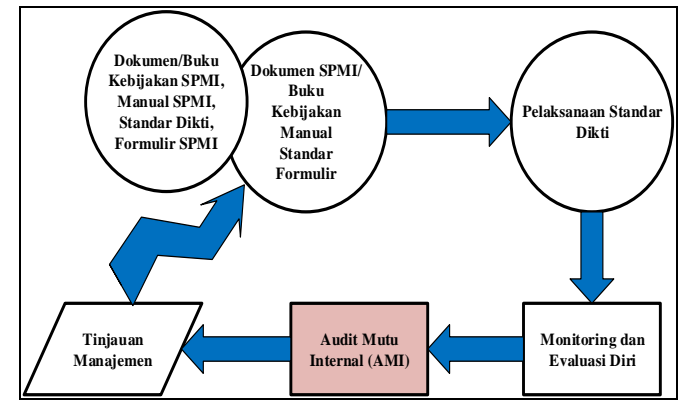

Gambar 1. Proses dalam SPMI

Gambar 1 dapat dipahami bahwa secara umum terdapat tiga proses yaitu perencanaan, kontrol dalam pelaksanaan, dan peningkatan dalam tindak lanjut. Ketiga proses tersebut harus terus disempurnakan guna mendapatkan hasil yang maksimal (Hamengkubuwono, 2017). Salah satu upaya yang dilakukan adalah dengan pemanfaatan teknologi informasi. Sistem ini dibangun dengan tujuan untuk memenuhi kebutuhan kualitas informasi, adapun beberapa hal yang diharapkan diantaranya informasi yang diberikan memenuhi kebutuhan pengguna. Informasi up to date. Menyediakan informasi yang akurat, relevan secara detail dan mudah dipahami serta disajikan sesuai standar format yang diberlakukan (Yodi, 2018). Menurut Willdahlia segala kegiatan yang berkaitan dengan efektifitas manajemen dalam suatu institusi dapat dibantu dengan pelaksanaan audit mutu internal (Willdahlia, 2017). Oleh sebab itu untuk mempertahankan dan meningkatkan kualitas manajemen dapat diukur proses audit mutu internal dengan variabel bahwa auditor internal mampu berkomunikasi dan bekerja sama dengan efektif dan benar. Terdapat beberapa hal yang harus dievaluasi terkait kegiatan AMI diantaranya :

1. Tim auditor memerlukan pemahaman secara mendalam berkaitan dengan peraturan dan kebijakan yang berlaku dalam suatu institusi untuk mendapatkan hasil audit yang lebih akurat terhadap informasi yang diberikan auditee.

2. Perlu adanya reward atau penghargaan untuk dosen dan tenaga kependidikan yang berprestasi dan punishment atau sanksi yang diberikan untuk dosen dan tenaga kependidikan yang tidak dapat menjalankan tanggung jawab dengan semestinya.

3. Tim auditor perlu menambah penalaman dan pengetahuan agar terus menjadi lebih baik dengan selalu mengikuti pelatihan-pelatihan yang berkaitan dengan audit mutu internal meskipun telah tersertifikasi

\subsection{Prosedur Penelitian}

Adapun tahapan prosedur yang dilakukan dalam penelitian ini, sebagaimana Gambar 2 (Marfuah et.al, 2017).

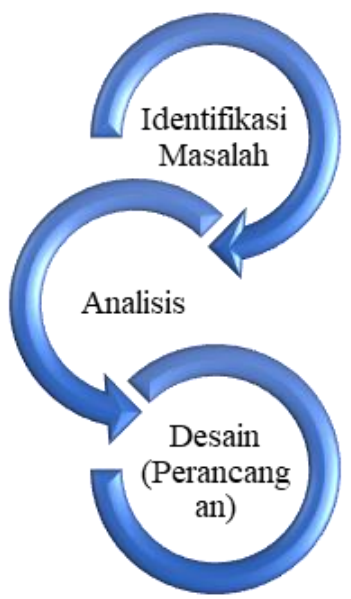

Gambar 2. Prosedur Penelitian 
Berdasarkan gambar 2 tahapan awal penelitian dilakukan dengan identifikasi masalah. Identifikasi masalah dilakukan dengan beberapa teknik pengumpulan data untuk memahami lebih dalam mengenai proses bisnis yang ada. Kemudian tahap selanjutnya yaitu melakukan analisis terhadap permasalahan yang ditemukan untuk mendapatkan solusi yang tepat. Setelah mendapatkan solusi maka tahapan ke tiga ialah membangun desain perancangan sistem menggunakan UML untuk menghaasilkan desain sistem baru yang mampu menyelesaikan permasalahan yang terjadi.

\subsection{Teknik Pengumpulan Data}

Pada penelitian ini pengumpulan dan analisis data menggunakan beberapa teknik diantaranya (Rusdiana et.al, 2018):

1. Kepustakaan (Library): Mempelajari dan mengumpulkan data melalui buku-buku, jurnal, dan terkait undang-undang yang berlaku terkait AMI perguruan tinggi, Standar Penjaminan Mutu Internal (SPMI).

2. Pengamatan (Observation): Melakukan pengambilan data lebih lanjut dengan terjun langsung ke lapangan untuk melihat proses AMI di perguruan tinggi Universitas Universal.

3. Wawancara (Interview): Melakukan pengumpulan data dengan cara melakukan tanya jawab secara langsung dengan tim Lembaga Penjaminan Mutu (LPM) internal perguruan tinggi, para auditor dan para auditi yang terlibat dalam suatu lembaga yang memberlakukan proses audit.

\section{HASIL DAN PEMBAHASAN}

\subsection{Hasil}

Pembangunan rancang bangun sistem khususnya dalam AMI berbasis IAPS 4.0, perlu kerangka pikir sistem yang menggambarkan bagaimana aktivitas sistem yang akan dikembangkan, sebagaimana terlihat pada Gambar 3.

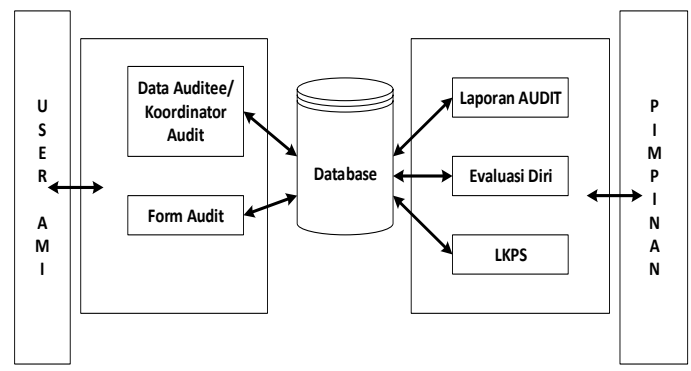

\section{Gambar 3. Kerangka berpikir sistem AMI}

Gambar 3 memperlihatkan integrasi sistem dalam suatu operasi dan pengelolaan data pada aktivitas bisnis secara otamatisasi, sehingga data yang diperoleh benar-benar akurat dan tepat. Pengendalian aktivitas bisnis dapat terwujud apabila pendistribusian data dan integrasi sistem antar pengguna berjalan dengan baik, hal ini juga dapat mendukung pengambilan keputusan oleh jajaran manajemen puncak. Adapun visual use case diagram sebagaimana gambar 4.

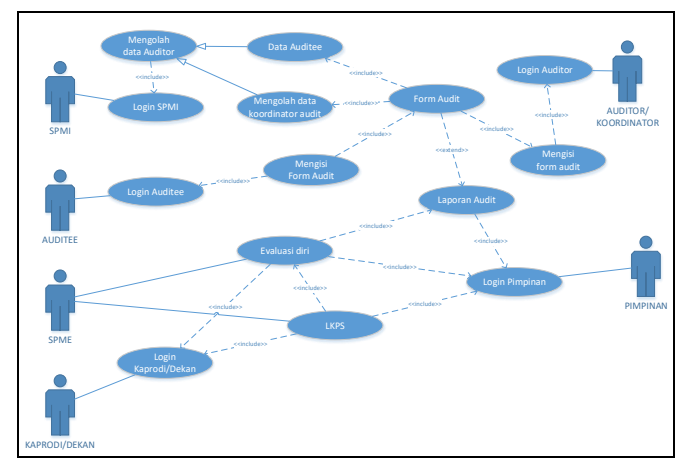




\section{Gambar 4. Diagram use case sistem}

Gambar 4 memperlihatkan bahwa terdapat beberapa aktor yang terlibat diantaranya SPMI, auditee, auditor, pimpinan, kaprodi atau dekan dan SPME yang merupakan pihak eksternal. Berikut merupakan sequence diagram SPMI gambar 5.

Gambar 4 memperlihatkan bahwa terdapat beberapa aktor yang terlibat diantaranya SPMI, auditee, auditor, pimpinan, kaprodi atau dekan dan SPME yang merupakan pihak eksternal. Gambar berikut merupakan sequence diagram SPMI.

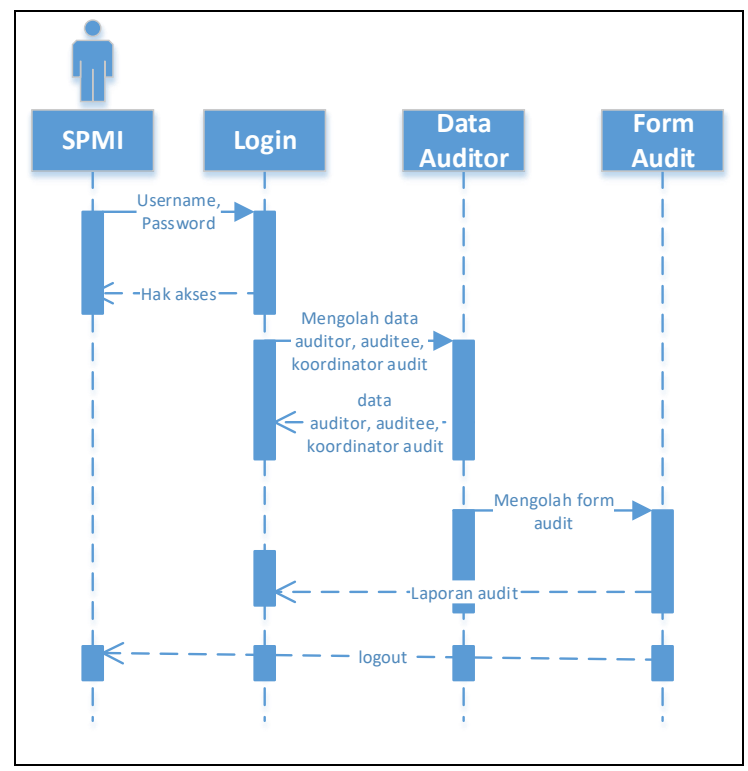

Gambar 5. Diagram sequence SPMI

Gambar 5 aktivitas sistem yang dilakukan oleh SPMI yaitu sebagai lembaga yang mengkoordinir jalan nya Audit Mutu Internal Perguruan Tinggi. Aktivitas yang dilakukan diantaranya mengelola data auditor, auditee dan koordinator audit pada tiap periode kegiatan audit yang diselenggarakan. Mengolah formulir atau borang audit yang nantinya akan diisi oleh auditor atau koordinator audit, auditee dan koordinator audit untuk menghasilkan laporan audit.

Diagram sequence auditor / koordinator / auditee sebagaimana diperlihatkan pada gambar 6. Dalam gambar 6 terlihat bahwa aktor auditor, koordinator dan auditee mengisi form audit untuk menghasilkan laporan audit. Diagram sequence Kaprodi atau Dekan dapat dilihat pada gambar 7.

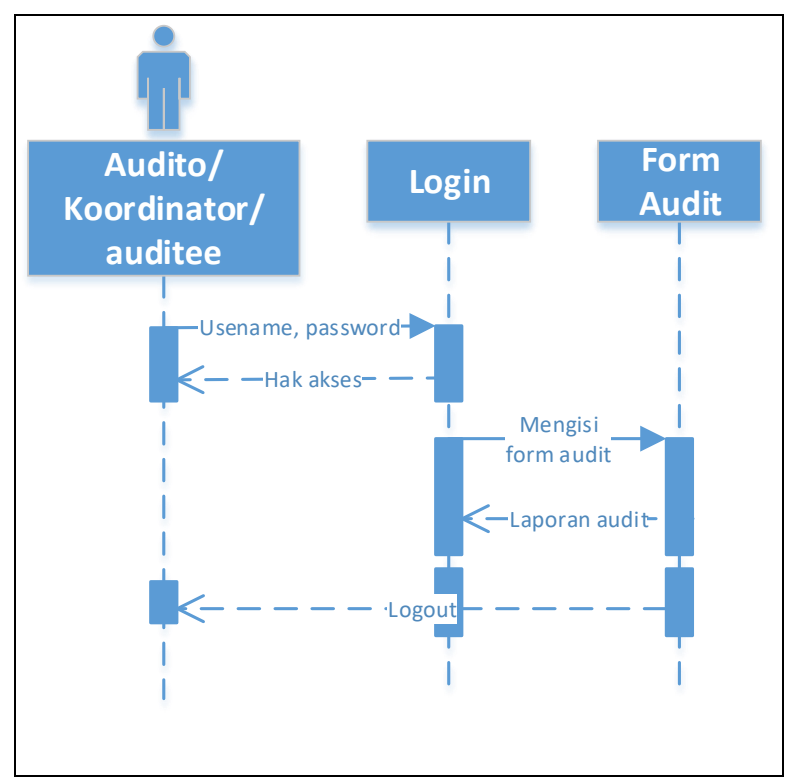


Gambar 6. Diagram sequence auditor / coordinator / auditee

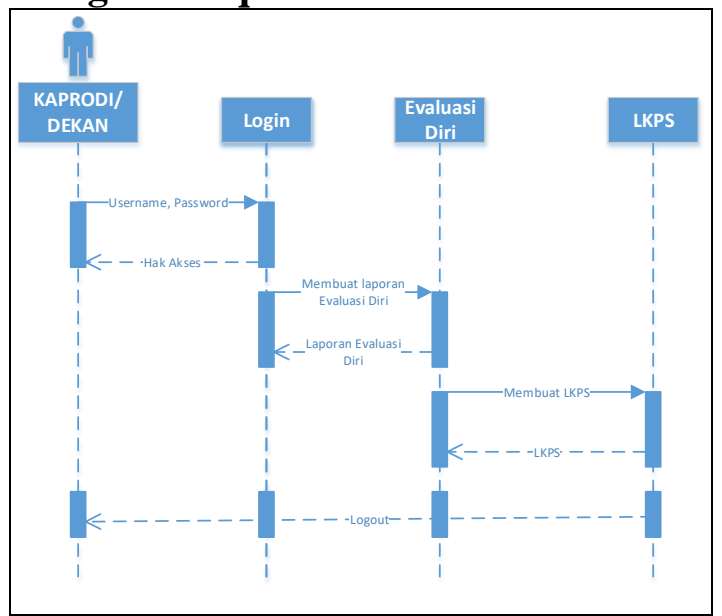

\section{Gambar 7. Diagram sequence Kaprodi / Dekan}

Gambar 7, Kaprodi atau Dekan dapat melakukan login kesistem dan kemudian membuat laporan evaluasi diri berdasarkan laporan audit sebelumnya. Kemudian Kaprodi atau Dekan juga dapat membuat Laporan Kinerja Program Studi (LKPS). Sequence diagram pimpinan sebagaimana gambar 8 .

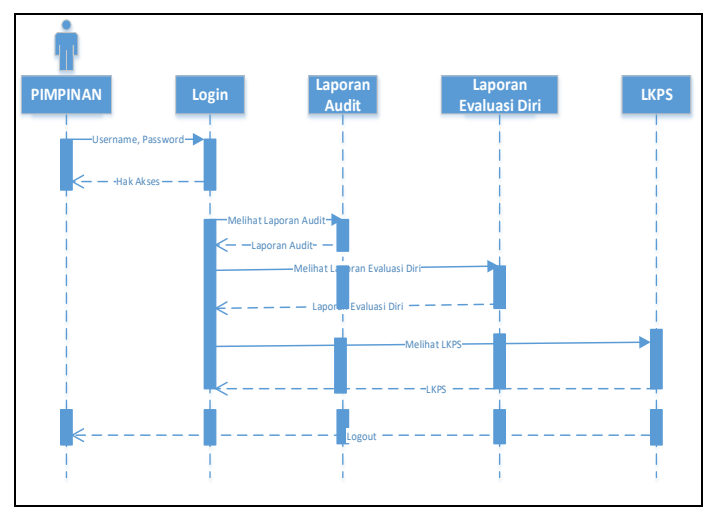

Gambar 8. Diagram sequence Pimpinan

Gambar 8 memperlihatkan bahwa aktor pimpinan bisa melakukan akses ke dalam sistem dengan melakukan login. Kemudian pimpinan bisa melihat laporan audit, laporan evaluasi diri dan LKPS dari masing-masing prodi yang ada. Sequence diagram Sistem Penjaminan Mutu Eksternal (SPME) sebagaimana gambar 9.

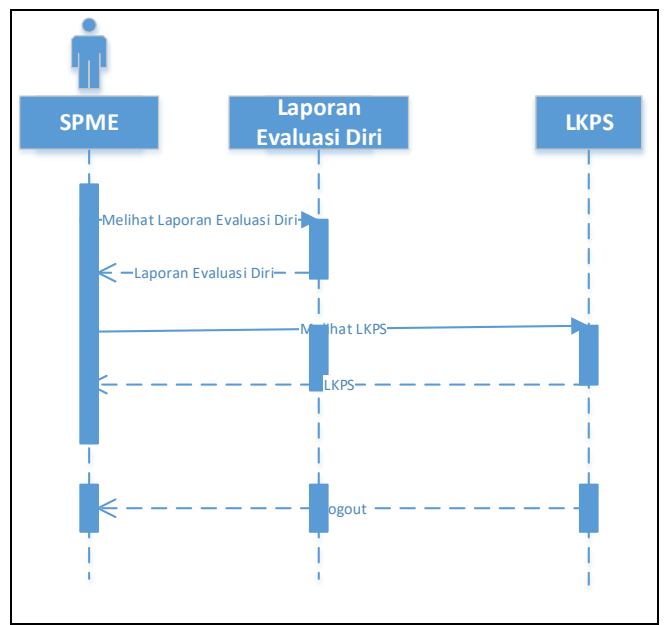




\section{Gambar 9. Diagram sequence sistem penjamin mutu eksternal (SPME)}

Gambar 9 menggambarkan bagian dari lingkungan luar sistem yang berperan sebagai SPME yang melakukan penilaian akreditasi. Aktor ini dapat melihat laporan evaluasi diri dan LKPS pada satu atau beberapa program studi dalam suatu perguruan tinggi. Secara umum gambaran ilustrasi sistem sebagaimana Gambar 10.

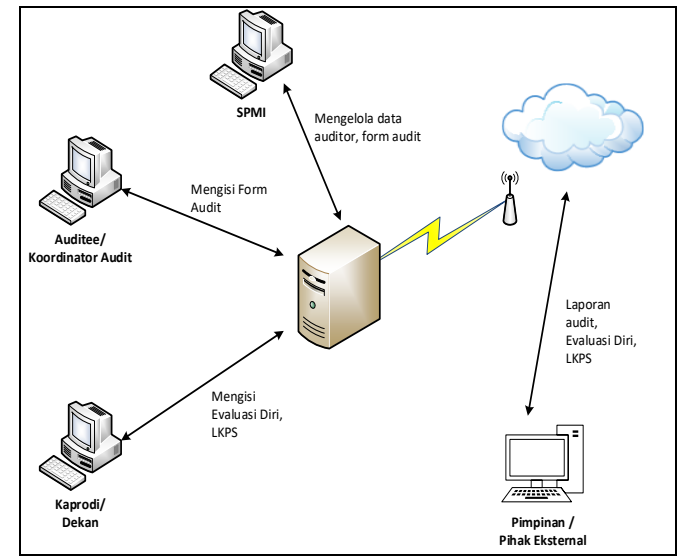

Gambar 10. Ilustrasi sistem dalam jaringan

\subsection{Pembahasan}

Penelitian ini dilakukan dengan tahap awal identifikasi masalah yang kemudian dianalisis lebih lanjut untuk di buat rancang bangun sistem dengan model UML, dimana UML yang digunakan adalah use case diagram dan sequence diagram. Use case diagram digunakan untuk menggambarkan hubungan antara aktor dengan entitasnya sehingga terlihat interaksi dan hubungannya. Sedangkan Sequence diagram digunakan untuk menampilkan secara lebih terperinci hubungan langsung antara aktor dan entitas baik secara langsung maupung tidak langsung.

\section{KESIMPULAN}

Dari hasil pembahasan yang telah dilakukan maka dapat diambil beberapa kesimpulan yaitu sebagai berikut:

1. Rancangan konseptual ini diharapkan dapat mempermudah untuk membangun sistem sesuai kebutuhan. Sehingga gambaran rancangan yang dibangun berdasarkan proses AMI yang sesungguhnya di Universitas Universal.

2. Kerangka pikir sistem terintegrasi di rancang untuk pengendalian aktivitas bisnis secara otamatisasi agar pendistribusian data dan integrasi sistem antar pengguna berjalan dengan baik dan efisien.

3. Rancangan ilustrasi sistem memperlihatkan cara kerja implementasi sistem terhadap beberapa user yang terlibat dalam melakukan interaksi yang akan menyimpan data dalam suatu server dan bagaimana informasi diakses sebagai keluaran dari sistem untuk mendukung pengambilan keputusan oleh jajaran top level manajemen dan stakeholder.

Berdasarkan hasil dan kesimpulan pada penelitian ini, maka dapat dikemukakan beberapa saran terkait pengembangan penelitian kedepan, diantaranya:

1. Perluasan ruang lingkup dalam pelaporan hingga menghasilkan Laporan Kinerja Perguruan Tinggi (LKPT).

2. Memperkuat basis sistem keamanan terkait sistem informasi.

3. Membangun sistem berdasarkan hasil rancangan yang sesuai.

4. Melakukan pengujian terkait kinerja sistem AMI yang dibangun.

\section{UCAPAN TERIMAKASIH}


Terimakasih kepada KEMENRISTEK DIKTI atas hibah penelitian Tahun Anggaran 2020, Lembaga Layanan Pendidikan Tinggi (LLDIKTI) wilayah X yang telah memberikan dukungan dana dan kesempatan untuk pelaksanaan penelitian ini

\section{DAFTAR PUSTAKA}

BAN-PT, (2019) ) “Peraturan Badan Akreditasi Nasional Perguruan Tinggi No 2 Tahun 2019.” BANPT.

A. K. Nugroho and P. K. Sari, (2016)“Analisis Pengaruh Kualitas Website Tokopedia Terhadap Kepuasan Pengguna Menggunakan Metode Webqual 4.0,” e-Proceeding Manag., vol. 3, no. 3, pp. 2930-2937.

Y. P. Fittryani and M. S. Ariantini, "Perancangan Distribusi Sistem Informasi untuk Optimalisasi Perubahan Jadwal Kuliah Berbasis Mobile Android (Studi Kasus: STIKI Indonesia)," J. Teknol. Inf. dan Komput., vol. 6, no. 2, pp. 208-217.

A. Cakra, M. L. Radhitya, and K. L. Maswari, "Rancang Bangun Sistem Informasi Pengolahan Nilai Siswa pada SMK Kesehatan Panca Atma Jaya,” pp. 245-253.

A. Komarudin and T. H. P., "Pembangunan Website Dan Repositori Pada Sistem Penjamin Mutu (Spm) Universitas Jenderal Achmad Yani,” J. Muara, vol. 1, no. 1, pp. 164-174, 2017, doi: 10.24912/jmstkik.v1i1.427.

A. C. Nugraha and N. Syakrani, (2018) "Aplikasi Audit Mutu Internal Online Studi Kasus Spm Politeknik Negeri Bandung,” DIFUSI, vol. 1, no. 2.

Adelin and H. Effendi, (2017) "Aplikasi Audit Mutu Akademik Internal dengan Pendekatan Extreme Programming,” J. TI Atma Luhur, vol. 4, no. 1, pp. 13-24.

Marfuah and S. Widiantoro, "Rancang Bangun Aplikasi Perekrutan Pegawai Berbasis Web ( Studi Kasus Universitas Universal)," STMIK Palangka Raya, pp. 78-89,.

Utariani and Herkules, (2017) "Monitoring Bimbingan Skripsi Online Pada Sekolah Tinggi Manajemen Informatika dan Komputer (STMIK) Palangka Raya,” STMIK Palangka Raya.

A. Wijaya, E. P. Agustini, and E. Nardo, (2018) "Sistem Informasi Geografis Dalam Pemetaan Lahan Gambut di Kabupaten Musi Banyuasin,” J. RESTI (Rekayasa Sist. dan Teknol. Informasi), vol. 2, no. 1, pp. 330-336, Apr. 2018, doi: 10.29207/resti.v2i1.298.

D. W. T. Putra and R. Andriani, (2019) "Unified Modelling Language ( UML ) dalam Perancangan Sistem Informasi Permohonan Pembayaran Restitusi SPPD,” J. TEKNOIF, vol. 7, no. 1, pp. 32-39.

T. P. SPMI, (2019) "Pengertian Audit Mutu Internal ( AMI ).

Hamengkubuwono, (2017)“Evaluasi Penerapan Audit Mutu Internal Pada STAIN Curup," TADBIRJurnal Stud. Manaj. Pendidik., vol. 1, no. 01.

Y. Yodi, (2018) “Analisis Kualitas Situs Web Batampos Menggunakan Metode WebQual 4.0,” J. RESTI (Rekayasa Sist. dan Teknol. Informasi), vol. 2, no. 2, pp. 591-596, Aug. 2018, doi: 10.29207/resti.v2i2.501.

A. G. Willdahlia, (2017) "Analisis Peranan Audit Mutu Internal Sebagai Alat Bantu dalam Menunjang Efektivitas Manajemen,” vol. 3.

L. Rusdiana and H. Setiawan, (2018) "Perancangan Aplikasi Monitoring Kesehatan Ibu Hamil Berbasis Mobile Android," SISTEMASI, vol. 7, no. September, pp. 197-203. 